\title{
Análise do nível de implementação dos instrumentos básicos de gestão ambiental nos municípios nordestinos em 2017
}

Analysis of the level of implementation of basic environmental management instruments in northeast municipalities in 2017

Análisis del nivel de implementación de instrumentos básicos de gestión ambiental em municipios del noreste em 2017

Recebido: 31/08/2021 | Revisado: 07/09/2021 | Aceito: 10/09/2021 | Publicado: 12/09/2021

Lídia da Silva Azevedo

ORCID: https://orcid.org/0000-0002-4154-5205 Universidade Federal do Ceará, Brasil

E-mail: lidiasilva97@outlook.com

Janaildo Soares de Sousa

ORCID: https://orcid.org/0000-0002-3380-5660 Universidade Federal do Ceará, Brasil

E-mail: janaildo18@hotmail.com

José Natanael Fontenele de Carvalho

ORCID: https://orcid.org/0000-0003-3748-390X

Universidade Federal do Delta do Parnaíba, Brasil E-mail: natanaelfontenele@ufpi.edu.br

\begin{abstract}
Resumo
Este artigo teve como objetivo analisar o nível de implementação dos instrumentos básicos de gestão ambiental nos municípios nordestinos no ano de 2017. Para tanto, foram utilizados dados referentes à pesquisa Perfil dos Municípios Brasileiros - 2017 publicada pelo Instituto Brasileiro de Geografia e Estatística (IBGE). O trabalho adota como estratégia empírica, a criação do Índice de Gestão Ambiental (IGA) para os municípios do Nordeste. Os resultados obtidos mostram que o nível de implementação dos instrumentos de gestão considerados, apresentam em média, baixos índices nos municípios da região. Os municípios que implementaram os quatro instrumentos de gestão considerados apresentam percentual ínfimo em comparação com o todo. Observou-se ainda que o instrumento menos frequente é a existência de secretaria municipal exclusiva de meio ambiente. A partir da realização da pesquisa é possível concluir que os municípios do Nordeste ainda são omissos quanto à implementação dos instrumentos considerados e a falta de interesse das gestões públicas no tocante a gestão ambiental ainda é um entrave existente na maioria dos municípios.

Palavras-chave: Gestão ambiental municipal; Instrumentos; Implementação.
\end{abstract}

\begin{abstract}
This article aimed to analyze the level of implementation of basic environmental management instruments in northeastern municipalities in 2017. For this purpose, data from the survey Profile of Brazilian Municipalities - 2017 published by the Brazilian Institute of Geography and Statistics (IBGE) are used. The work adopts as an empirical strategy, the creation of the Environmental Management Index (IGA) for municipalities in the Northeast. The results obtained show that the level of implementation of the considered management instruments have, on average, low rates in the region's municipalities. Municipalities that implemented the four management instruments considered percentages compared to the whole. It was also observed that the less frequent instrument is the existence of an exclusive municipal secretariat for the environment. Based on the research, it is possible to observe that municipalities in the Northeast are still silent on the implementation of the instruments considered and the lack of interest from public administrations regarding environmental management is still an obstacle in most municipalities.
\end{abstract}

Keywords: Municipal environmental management; Instruments; Implementation.

\section{Resumen}

Este artículo tuvo como objetivo analizar el nivel de implementación de los instrumentos básicos de gestión ambiental en los municipios del Nordeste en 2017. Para ello, los datos de la encuesta Perfil de los Municipios Brasileños - 2017, publicada por el Instituto Brasileño de Geografía y Estadística (IBGE) son utilizado. El trabajo adopta como estrategia empírica la creación del Índice de Gestión Ambiental (IGA) para los municipios del Nordeste. Los resultados obtenidos muestran que el nivel de implementación de los instrumentos de gestión considerados presenta, en promedio, tasas bajas en los municipios de la región. Los municipios que implementaron los cuatro instrumentos de gestión consideraron porcentajes con relación al total. También se observó que el instrumento menos frecuente es la existencia de una secretaría municipal exclusiva para el medio ambiente. Con base en la investigación, es posible observar que los 
municipios del Nordeste aún guardan silencio sobre la implementación de los instrumentos considerados y el desinterés de las administraciones públicas por la gestión ambiental sigue siendo un obstáculo en la mayoría de los municipios.

Palabras clave: Gestión ambiental municipal; Instrumentos; Impementación.

\section{Introdução}

A Revolução Industrial pode ser considerada como marco histórico determinante para o aumento da preocupação acerca da exploração dos recursos naturais. Poluição, vazamento de produtos químicos e contaminações dos rios estimularam a discussão sobre os desgastes de recursos e as possíveis formas de remediação ou prevenção que visassem amenizar os resultados catastróficos causados pela industrialização (Pott \& Estrela, 2017).

A partir da década de 1960 os debates acerca da utilização desenfreada dos recursos naturais se ampliaram, com o lançamento do livro "Primavera Silenciosa", de Rachel Carson (Bonzi, 2013). Contudo, foi no ano de 1972 que o cenário ambiental mundial tomou novos rumos, ano da realização da Conferência de Estocolmo, a qual buscou estabelecer uma visão global e de princípios comuns para a preservação e melhoria do ambiente humano (Tannous \& Garcia, 2008). De acordo com Cezaré (2009) a força que a questão ambiental adquiriu após os eventos relacionados ao meio ambiente colocou um "novo referencial e responsabilidade para a gestão e para o planejamento urbano e, consequentemente, metropolitano em face dos conflitos socioambientais" (p. 15).

Em resposta à Conferência de Estocolmo, diversos países institucionalizaram instâncias para tratarem do meio ambiente. No caso brasileiro, foi criada a Secretaria Especial do Meio Ambiente no ano de 1973 (Barbieri, 2016). No entanto, prevalecia ainda a ausência de uma política ambiental efetiva, tendo em vista a falta de instrumentos básicos de gestão ambiental. Em sua definição, a gestão ambiental pode ser entendida como:

[...] as diretrizes e as atividades administrativas e operacionais, tais como o planejamento, direção, controle, alocação de recursos e outras realizadas com o objetivo de obter efeitos positivos sobre o meio ambiente, tanto reduzindo, eliminando ou compensando os danos ou problemas causados pelas ações humanas, quanto evitando que eles surjam. (Barbieri, 2011, p. 19).

Com a implementação da Constituição Federal de 1988 - CF/88 ocorre o processo de descentralização e democratização de políticas públicas em todas as áreas. No tocante à gestão ambiental, a CF/88 deixa claro, no Art. $n^{\circ} 225$ inciso III, que o meio ambiente é assunto de interesse comum de todos os entes federados. Portanto, o legislador evidencia de forma implícita que o Município é também responsável pela gestão ambiental. Desse modo, os municípios são reconhecidos enquanto entes federados e responsáveis por um conjunto de competências para as mais diversas políticas públicas (Leme, 2010; Leme, 2016). O processo de descentralização serviu de fomento à criação de instrumentos de gestão que favorecem a implementação de políticas públicas setoriais (Sousa et al. 2017).

Desse modo, "o governo municipal adquire um papel central como stakeholder, em decorrência do contato em primeira instância com os problemas urbano-ambiental de sua população" (Rodrigues et al, 2016, p. 102). Para cumprir esse mister o Estado necessita implementar mecanismos básicos de gestão ambiental, como: (i) Secretaria Municipal do Meio Ambiente; (ii) Conselho Municipal; (iii) Fundo Municipal e (iv) Plano de Gestão Integrada dos Resíduos Sólidos. Além disso, é preciso fortalecer estas ações via parcerias com o estado em que o Município está inserido, pois o planejamento ambiental perpassa o território municipal (LEME, 2010).

Conforme salienta Bittar (2016, p. 13) "a proteção ao meio ambiente é inerente ao conceito de desenvolvimento sustentável, o que atribui à administração pública o dever de se orientar por esse conceito". Sendo assim, a capacidade instalada dos municípios para lidar com a gestão ambiental por meio dos instrumentos de gestão - existência de órgão gestor qualificado, fundo municipal, legislação ambiental e conselho municipal - influencia diretamente o tipo de gestão ambiental a ser promovida nos diferentes municípios (Leme, 2010). 
Conforme destacam Rodrigues et al. (2016), a implementação dos mecanismos básicos de gestão ambiental, no semiárido brasileiro é um pouco preocupante. Além disso, não se tem clareza da situação institucional ambiental da Região Nordeste. Nessa perspectiva, levanta-se a seguinte problemática: qual o nível de implementação dos mecanismos básicos de gestão ambiental nos municípios nordestinos em 2017?

O presente estudo objetiva, portanto, analisar o nível de implementação dos mecanismos básicos de gestão dos Municípios Nordestinos no ano de 2017. Especificamente, abordar a gestão ambiental pública e as políticas públicas ambientais no Brasil; criar do índice de Gestão Ambiental (IGA) para os municípios nordestinos; verificar os municípios com maiores e menores níveis de implementação dos mecanismos básicos de gestão ambiental; e identificar quais instrumentos são mais e menos implementados.

\section{Metodologia}

Do ponto de vista da abordagem do problema, a pesquisa assume caráter quantitativo. Nesse sentido, considera o que pode ser quantificável e traduz em números informações para classificá-las e analisá-las, utilizando-se para tanto, de recursos e técnicas estatísticas (Prodanov \& Freitas, 2013). A pesquisa adotou como unidade de observação os 1.794 municípios nordestinos ${ }^{1}$. No entanto, devido ao número de municípios, os resultados obtidos são discutidos em escala estadual. A escolha em adotar os municípios da Região Nordeste partiu do pressuposto que em áreas áridas e semiáridas o efeito da degradação dos recursos ambientais é mais preocupante, dado os seus ecossistemas. (Rodrigues et al, 2016). Além disso, conforme Carvalho et al (2005) a gestão local do meio ambiente na Região Nordeste é algo que precisa ser fortalecida.

Os dados utilizados foram extraídos da pesquisa "Perfil dos Municípios Brasileiros -, 2017" - publicada pelo Instituto Brasileiro de Geografia e Estatística - IBGE (IBGE, 2017). A pesquisa traz as informações mais recentes sobre os principais instrumentos de gestão municipal do Meio Ambiente, dentre outras vertentes. A adoção da referida pesquisa é justificável pelo fato desta ser a base de dados mais recente sobre a temática ambiental em escala municipal.

\subsection{Mensuração dos mecanismos de gestão municipal do meio ambiente nos estados nordestinos}

Para avaliar o nível de implementação dos mecanismos básicos de gestão municipal do meio ambiente optou-se por considerar indicadores expostos no Quadro 1, os quais foram a base da construção do Índice Gestão Ambiental - IGA nos municípios nordestinos. Os indicadores selecionados interferem direta e indiretamente na política ambiental em escala local (Leme, 2010). Três critérios principais foram determinantes na escolha de cada indicador: consistência com a fundamentação teórica, confiabilidade das informações e disponibilidade de dados em nível municipal (Booysen, 2002; Jacobs; Goddard, 2007; Braga, 2012).

Quanto à aplicabilidade do IGA, coloca-se o seu potencial para avaliação de um modelo municipal de gestão no qual, segundo Miranda (2012), o governo municipal adquire um papel central, devido ao contato em primeira instância com os problemas urbano-ambiental. Assim, o IGA é resultado da agregação dos 4 indicadores expostos no Quadro 1. É necessário ressaltar que o IGA não tem a pretensão de qualificar a gestão ambiental dos municípios nordestinos, mas hierarquizar e comparar os municípios e estados da Região Nordeste, de acordo com a implementação dos instrumentos de gestão, o que, em primeira instância, constitui o passo inicial para a criação de condições necessárias à prática de uma gestão ambiental eficiente e o fortalecimento da PNMA.

\footnotetext{
${ }^{1}$ Conforme a distribuição geográfica utilizada pelo Instituto Brasileiro de Geografia e Estatística - IBGE.
} 
Quadro 1 - Indicadores componentes do Índice de Gestão Ambiental (IGA).

\begin{tabular}{|l|c|}
\hline \multicolumn{1}{|c|}{ Indicadores } & Operacionalização dos indicadores \\
\hline $\begin{array}{l}1 \text { - Existência -Secretaria municipal exclusiva do meio } \\
\text { ambiente }\end{array}$ & $X_{i, 1}=\left\{\begin{array}{c}1-\text { Existência do indicador } \\
0-\text { Ausência do indicador }\end{array}\right.$ \\
\hline 2 - Existência - Conselho Municipal de Meio Ambiente & $X_{i, 2}=\left\{\begin{array}{c}1-\text { Existência do indicador } \\
0-\text { Ausencia do indicador }\end{array}\right.$ \\
\hline 3 - Existência de Fundo Municipal de Meio Ambiente & $X_{i, 3}=\left\{\begin{array}{c}1-\text { Existência do indicador } \\
0-\text { Ausencia do indicador }\end{array}\right.$ \\
\hline $\begin{array}{l}4 \text { - O município possui Plano de Gestão Integrada de } \\
\text { Resíduos Sólidos nos termos estabelecidos na Política } \\
\text { Nacional de Resíduos Sólidos. }\end{array}$ & $X_{i, 4}=\left\{\begin{array}{c}1-\text { Existência do indicador } \\
0-\text { Ausencia do indicador }\end{array}\right.$ \\
\hline
\end{tabular}

Fonte: Elaboração própria a partir Pesquisa Perfil dos Municípios Brasileiros - 2017 (IBGE, 2017).

O IGA é resultado da agregação dos 4 indicadores expostos no Quadro 1. Conforme adaptação de metodologia apresentada em Toledo (2005) e Rodrigues et al. (2016), onde o indicador recebeu escore 1 (um) quando observada a sua existência na gestão municipal e escore 0 (zero), em caso de sua ausência.

\subsection{Método da construção do índice de gestão ambiental - IGA/NE nos municípios nordestinos}

Após a seleção dos indicadores, o procedimento seguinte foi o cálculo do Índice de Gestão Ambiental. O cálculo do IGA seguiu o procedimento adotado por Lima et al. (2014); Sousa, Lima e Khan (2015); Rodrigues et al. (2016) e Sousa et al (2018) por meio da expressão:

$$
I G A_{i}=\sum_{i=1}^{p} \frac{E_{i j}}{E_{\max i}}
$$

Sendo:

$\mathrm{IGA}_{\mathrm{j}}=$ Índice de Gestão Ambiental no i-ésimo município.

$\mathrm{E}_{\mathrm{ij}}=$ escore correspondente aoo $i$-ésimo indicador obtido pelo $j$-ésimo município ( 0 para ausência do instrumento no município ou 1 para a existência)

$\mathrm{E}_{\mathrm{maxi}}=$ escore máximo do $i$-ésimo indicador

$\mathrm{i}=1, \ldots \ldots . ., \mathrm{p}$, número de indicadores (4)

$\mathrm{j}=1, \ldots \ldots \ldots, \mathrm{n}$, número de municípios da Região Nordeste (1.794)

Após o cálculo do IGA para cada município obteve-se, por meio de média aritmética, o IGA para cada estado nordestino (Sousa; Lima \& Khan, 2015):

$$
I G A=\sum_{J=1}^{1794} I G A_{j} / j
$$

Para todos os índices calculados, quanto mais próximo de 1, melhor a situação do município. Ademais, quando multiplicado por 100, o IGA pode ser interpretado como o percentual de implementação dos mecanismos municipais da gestão ambiental nos municípios nordestinos (Rodrigues et al., 2016; Sousa et al., 2017).

\section{Resultados e Discussão}

A Política Nacional do Meio Ambiente, Lei Federal n 6.938, foi implementada com o intuito de estabelecer princípios, diretrizes, instrumentos e atribuições para os diferentes entes federados tendo em vista maior eficiência no gerenciamento dos 
recursos naturais (Moura, 2016). A referida Lei "não só estabeleceu os princípios, objetivos e instrumentos da Política Nacional do Meio Ambiente, como ainda incorporou, de vez, no ordenamento jurídico brasileiro o Estudo de Impacto Ambiental, instituindo, ademais, um regime de responsabilidade civil objetiva para o dano ambiental, sem falar que lhe coube conferir ao Ministério Público, pela primeira vez, legitimação para agir nessa matéria. (Benjamin, 1999. p. 98).

O artigo nº 225 da CF/88 aborda a questão ambiental e as incumbências do poder público no referente a ela:

"I - preservar e restaurar os processos ecológicos essenciais e prover o manejo ecológico das espécies e ecossistemas; II - preservar a diversidade e a integridade do patrimônio genético do País e fiscalizar as entidades dedicadas à pesquisa e manipulação de material genético; III - definir, em todas as unidades da Federação, espaços territoriais e seus componentes a serem especialmente protegidos, sendo a alteração e a supressão permitidas somente através de lei, vedada qualquer utilização que comprometa a integridade dos atributos que justifiquem sua proteção; IV - exigir, na forma da lei, para instalação de obra ou atividade potencialmente causadora de significativa degradação do meio ambiente, estudo prévio de impacto ambiental, a que se dará publicidade; V - controlar a produção, a comercialização e o emprego de técnicas, métodos e substâncias que comportem risco para a vida, a qualidade de vida e o meio ambiente; VI - promover a educação ambiental em todos os níveis de ensino e a conscientização pública para a preservação do meio ambiente; VII - proteger a fauna e a flora, vedadas, na forma da lei, as práticas que coloquem em risco sua função ecológica, provoquem a extinção de espécies ou submetam os animais a crueldade" (Brasil, 1988. p. 131).

Com a promulgação da $\mathrm{CF} / 88$, os municípios passaram a dispor de maior autonomia na elaboração e execução de políticas públicas em várias áreas, inclusive às ambientais. Por conta disso, verificou-se como necessária a implementação de instrumentos de gestão ambiental a nível local que facilitassem o planejamento, execução e monitoramento delas. No entanto, a partir da análise considerada, é possível observar que ainda é consideravelmente pequeno o número de prefeituras que implementam os mecanismos analisados quanto ao nível de gestão ambiental.

A Tabela 1 relaciona o IGA que expressa, em termos médios, o grau de adoção nos municípios que compõem os estados da Região Nordeste dos quatro instrumentos de Gestão Municipal Ambiental analisados. Observa-se que mesmo após três décadas da instituição da PNMA, o nível de implementação dos instrumentos que podem favorecer o município no tocante à gestão ambiental é consideravelmente baixo. Essa realidade é preocupante, tento em vista que, conforme Rodrigues et al. (2016, p. 103), "na ausência de instrumentos eficientes de gestão ambiental, a degradação dos recursos naturais alcança níveis alarmantes de insustentabilidade, ameaçando a população regional e comprometendo a estabilidade socioeconômica dos municípios".

Ademais, verifica-se uma elevada heterogeneidade no nível de implementação da gestão ambiental nos municípios nordestinos, tento em vista que o valor do coeficiente de variação - CV é superior a 30\% e, portanto, há uma alta dispersão dos dados. Os casos mais extremos são dos municípios do estado do Piaúi ( $\mathrm{CV}=125,25 \%)$; nos municípios pernambucanos (CV= 98,53\%) e nos municípios paraibanos (CV=94,35\%). 
Tabela 1 - Estatística descritiva do IGA dos estados nordestinos.

\begin{tabular}{c|c|c|c|c|c|c}
\hline Estados & $\begin{array}{c}\text { Total de } \\
\text { Municípios }\end{array}$ & $\begin{array}{c}\text { Índice Médio da Gestão } \\
\text { Ambiental - IGA }\end{array}$ & Mediana & Mínimo & Máximo & $\begin{array}{c}\text { Coeficiente de } \\
\text { Variação - CV }(\%)\end{array}$ \\
\hline Maranhão & 217 & 0,38 & 0,25 & 0,00 & 1,00 & 82,54 \\
\hline Piauí & 224 & 0,20 & 0,00 & 0,00 & 1,00 & 125,25 \\
\hline Ceará & 184 & 0,50 & 0,50 & 0,00 & 1,00 & 55,23 \\
\hline $\begin{array}{c}\text { Rio Grande do } \\
\text { Norte }\end{array}$ & 167 & 0,28 & 0,25 & 0,00 & 1,00 & 88,93 \\
\hline Paraíba & 223 & 0,24 & 0,25 & 0,00 & 1,00 & 94,35 \\
\hline Pernambuco & 185 & 0,29 & 0,25 & 0,00 & 1,00 & 98,53 \\
\hline Alagoas & 102 & 0,32 & 0,25 & 0,00 & 1,00 & 82,52 \\
\hline Sergipe & 75 & 0,52 & 0,50 & 0,00 & 1,00 & 52,78 \\
\hline Bahia & 417 & 0,47 & 0,50 & 0,00 & 1,00 & $\mathbf{0 1 , 0 0}$ \\
\hline Nordeste & $\mathbf{1 . 7 9 4}$ & $\mathbf{0 , 3 6}$ & $\mathbf{0 , 2 5}$ & $\mathbf{0 , 0 0}$ & $\mathbf{1 , 0 0}$ \\
\hline
\end{tabular}

Fonte: Autores com base nos dados do IBGE (2017).

Os resultados apresentados para os estados da Região Nordeste são alarmantes. Analisando os valores obtidos da mediana (Mediana do IGA=0,25) nota-se que mais de 50\% dos estados que compõem a Região Nordeste implementaram pelo menos um dos quatro instrumentos em análise. É possível verificar que mesmo com a legislação existente que fornece maior autonomia aos municípios, grande parte deles só implementa um instrumento de gestão, o que compromete a evolução da gestão ambiental pública no tocante ao gerenciamento dos recursos, além de demonstrar a omissão dos municípios dos respectivos estados no que se refere a promoção de políticas públicas ambientais em escala local.

No tocante aos municípios verificados, 26\% $(\mathrm{n}=469)$ deles não empregam nenhum dos quatro instrumentos considerados (IGA= 0,00 - Apêndice 2), como evidencia a Figura 1. Sendo que 51 são municípios do Maranhão; 115 do Piauí; 18 do Ceará; 54 do Rio Grande do Norte; 76 da Paraíba; 68 do Pernambuco; 27 de Alagoas; 6 de Sergipe e 54 do estado da Bahia.

Figura 1 - Total dos municípios por estado que não implementaram nenhum os instrumentos de gestão em análise (2017).

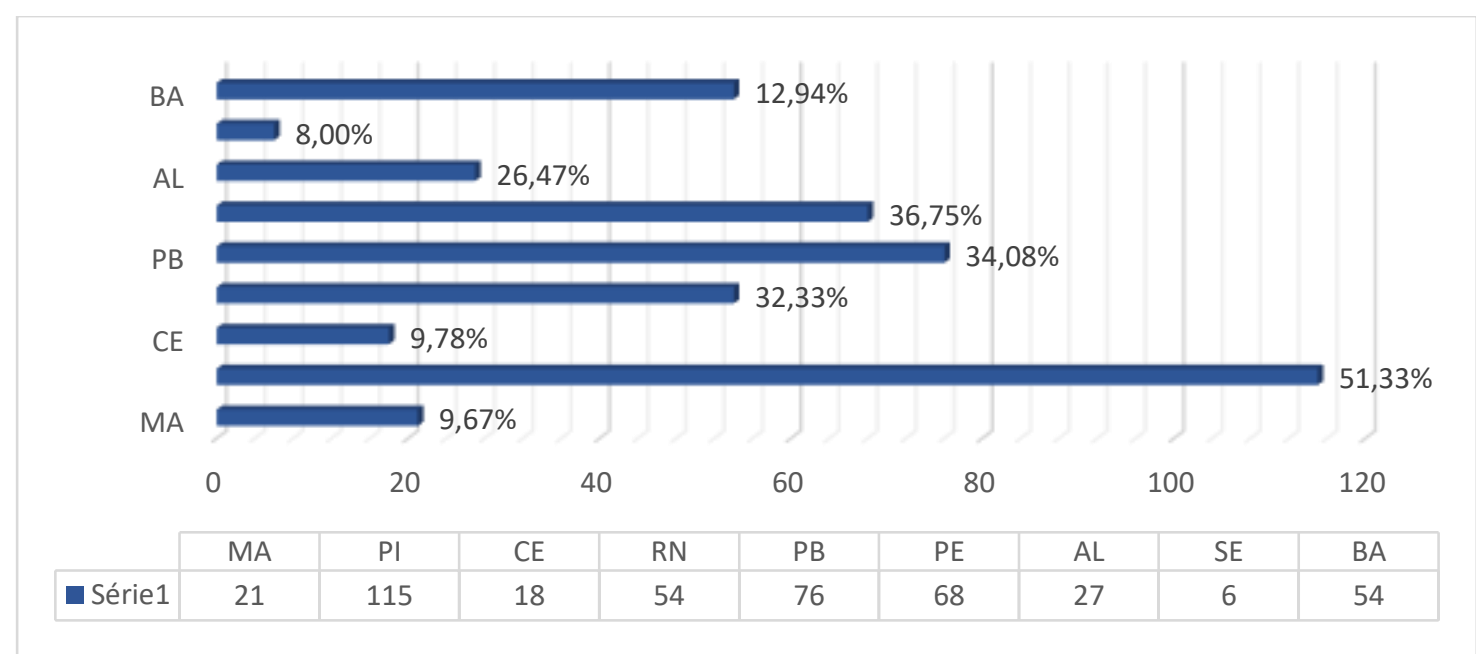

Fonte: Elaboração dos autores com base nos dados do IBGE (2017).

De forma análoga, tem-se o caso dos 70 municípios que implementaram 100\% dos quatro instrumentos em análise $(\mathrm{IGA}=1,00)$. Do total (70), cerca de 18 são municípios do estado do Maranhão; 3 do Piauí; 16 do Ceará; 2 do Rio Grande do Norte; 3 da Paraíba; 5 do Pernambuco; 2 de Alagoas; 6 de Sergipe e 15 da Bahia, respectivamente (Figura 2). 
Figura 2 - Total dos municípios por estado que implementaram todos os instrumentos de gestão em análise (2017).

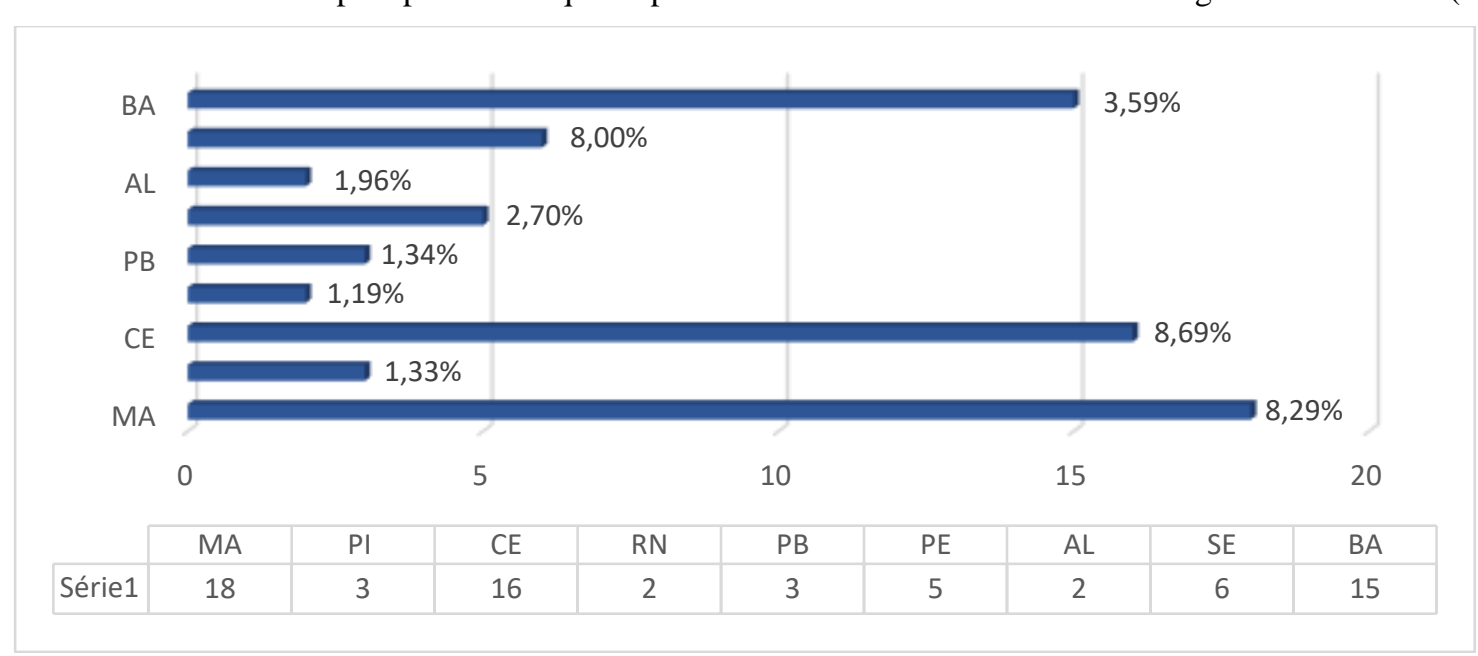

Fonte: Elaboração dos autores com base nos dados do IBGE (2017).

Um fator que pode ser considerado é a falta de estímulo das prefeituras na implementação, que podem se dar devido à falta de investimentos financeiros dispostos à administração pública para o gerenciamento ambiental ou devido ao investimento público ser destinado apenas a áreas consideradas primordiais como saúde e infraestrutura. Apesar disso, a CF/1988 no Art. 23 e no capítulo 30 deixam claro que políticas ambientais devem ser realizadas por todos os entes federados e, portanto, os municípios não podem ser omissos a essa responsabilidade em comum (Leme, 2016).

De acordo com Redin e Silveira (2012), a PNMA apresenta deficiências em sua constituição que acabam por influenciar negativamente o processo de implementação efetiva dos instrumentos de gestão. As três deficiências consideradas pelos autores são: o caráter tecnocrático, por privilegiar em sua constituição os aspectos considerados técnicos, deixando de lado as indicações de caráter social; a existência de restrições significativas para democratizar a participação mais ampla da sociedade; e o gerenciamento do componente, não as pessoas no espaço.

Analisando os estados do Nordeste que apresentam os maiores índices de gestão ambiental, verificam-se Sergipe (52\%) e Ceará (50\%), seguidos pela Bahia (47\%). O desempenho do estado de Sergipe pode estar atrelado à participação da população em conselhos e fóruns de discussão (Felizola; Costa, 2012), que fomentam o desenvolvimento e legitimam a importância da participação da sociedade na implementação de políticas junto ao setor público.

Quanto ao estado do Ceará, pode-se considerar que iniciativas para a implementação nas municipalidades de políticas públicas socioambientais tem gerado resultados quanto à estruturação da gestão ambiental local. Exemplo disso foi a instituição do Programa Selo Município Verde - Lei n 13.304/2003 - que objetivou incentivar os municípios no estabelecimento de políticas públicas ambientais tendo em vista melhorias no âmbito local. (Leme, 2016).

Apesar do estado do Ceará ser destaque em relação aos demais estados nordestinos no tocante à implementação dos instrumentos básicos de gestão, isso não o eleva a condição de ter uma gestão ambiental fortalecida. Além disso, dado o valor do IGA (0,50), isso evidencia que a gestão ambiental nos municípios nordestinos é ainda bastante precária, pois o nível de implementação dos instrumentos básicos de gestão em escala local ainda está muito aquém do esperado. Por exemplo, mesmo o estado do Ceará apresentando maiores níveis de implementação dos instrumentos básicos de gestão, ao considerar o todo, o nível de implementação ainda é baixo.

Um dos fatores que podem explicar o baixo índice ainda presente é o fato de os gestores públicos darem mais atenção a problemas ambientais que comprometem de forma mais direta a qualidade de vida das pessoas, a exemplo do saneamento básico e questões de infraestrutura. 
A maior fragilidade quanto ao IGA obtido encontra-se no estado do Piauí (20\%). A insuficiência tanto de recursos financeiros como de pessoal para exercer adequadamente as funções inerentes à gestão ambiental podem ser consideradas como fatores que influenciam negativamente o processo de descentralização das políticas públicas ambientais. Ademais, a ausência de vontade política dos prefeitos municipais de assumirem seu papel no SISNAMA pode ocasionar colapso no sistema estadual de meio ambiente e o conflito de competências nas atuações das diferentes esferas governamentais (Chiesa, 2013).

Quanto aos valores obtidos no coeficiente de variação, torna-se possível verificar o alto grau de heterogeneidade existente entre os municípios. É possível verificar também, os estados do Piauí, Pernambuco e Paraíba como possuidores dos menores IGA do Nordeste. Apesar das crescentes discussões acerca da temática ambiental, quando se relaciona a Região Nordeste, verifica-se que o percentual de atuação da gestão pública municipal no tocante ao IGA é consideravelmente baixo (36\%), o que acaba por demostrar que a utilização dos quatro instrumentos de gestão ambiental considerados não é prática comum nos mesmos. Conforme salienta Leme (2016), muitos são os entraves enfrentados pela gestão ambiental pública local, dentre eles, os mais evidentes são a falta de estrutura, pessoal e recursos.

A estruturação de políticas municipais de meio ambiente se faz imprescindível, "para que os governos locais encontrem, em conjunto com a comunidade, caminhos saudáveis para seu crescimento, superando o discurso tradicional de progresso a qualquer preço, questionando o desperdício e estabelecendo relação equilibrada com o meio ambiente” (Bruschi, et al., 2002, p. 10). Nesse sentido, a utilização de instrumentos para um melhor gerenciamento público ambiental oferta condições para que sejam evitados novos problemas ambientais, assim como para minimizar problemas já existentes (Barbieri, 2016). Verifica-se, com isso, a necessidade de que os municípios que compõem os estados com menores Índices de Gestão Ambiental atentem para a necessidade e importância da utilização dos instrumentos de gestão em suas políticas.

Outra forma de contribuição positiva no sentido da utilização de instrumentos de gestão é o diálogo entre os diferentes entes federados que compõem a Região Nordeste, tendo em vista melhorar a eficiência, eficácia e efetividade de políticas públicas ambientais (Leme, 2010). O diálogo entre os diferentes municípios pode ser favorável no tocante à observação de determinada política adotada, para que a partir dela seja possível elaborar políticas no próprio território ou discutir o estabelecimento de instrumentos de gestão que funcionem de forma efetiva.

\subsection{Proporção dos mecanismos básicos de gestão ambiental dos municípios nordestinos}

As políticas ambientais possuem cunho de complexidade e, portanto, devem ser concebidas de modo a dialogar com políticas setoriais, tendo em vista a incorporação de critérios ambientais na concepção de políticas públicas de desenvolvimento (Leme, 2010). Os mecanismos básicos de gestão analisados contribuem para a análise da situação dos municípios do Nordeste quanto ao estabelecimento de meios para o desenvolvimento sustentável com influência direta da gestão pública municipal.

Os instrumentos de gestão ambiental são os meios utilizados para atingir objetivos propostos por uma política ambiental e atuam no auxílio do processo de planejamento e na operacionalização da gestão ambiental, de modo que esta gestão possa ser integrada de maneira estratégica por todas as suas atividades (Nunes; Philippi JR; Fernandes, 2012; Boschetti; Bacarji, 2009). Por mais que a simples adoção dos instrumentos não altere a realidade do quadro ambiental, a existência deles favorece a dinamicidade da gestão pública ambiental em nível municipal.

A Tabela 2 especifica o percentual de implementação de cada um dos quatro instrumentos analisados nos estados nordestinos: (1) Existência de Secretaria Municipal exclusiva do Meio Ambiente; (2) Existência de Conselho Municipal de Meio Ambiente; (3) Existência de Fundo Municipal de Meio Ambiente; e (4) Existência de Plano de Gestão Integrada de Resíduos Sólidos.

A partir da análise, é possível observar que o Ceará é o estado que apresenta, em média, melhores indicadores quanto a implementação dos quatro instrumentos considerados. Dos municípios cearenses, 85,33\% contam com a existência de conselho 
municipal de meio ambiente, o que é favorável por conta de eles inovarem no sentindo de institucionalização do diálogo entre governo e sociedade, tendo em vista alocação mais justa e eficiente dos recursos públicos. (LEME, 2016). O segundo maior percentual quanto à existência de conselho é o da Bahia, com 84,41\%.

Dentre os estados que apresentam menores percentuais no tocante ao mesmo indicador encontram-se Piauí $(25,45 \%)$ e Paraíba (26,91\%). Leme (2010), em análise acerca dos conselhos ambientais, descreve que as prefeituras não têm motivação para a implementação de conselhos municipais de meio ambiente, uma vez que não há transferência de recursos ligados a sua existência. No entanto, com a instituição da Lei Complementar $n^{\circ}$ 140/2011, que estabeleceu a existência de conselhos municipais como condição para o município proceder ao licenciamento ambiental de atividades de impacto local, obtiveram-se melhorias no tocante a utilização desse instrumento nas gestões locais. (Rodrigues, et. al., 2016). No tocante aos municípios do Nordeste, ainda há deficiências a serem sanadas para que a existência deles se dê de forma exitosa.

Vícios antigos ainda existentes na administração pública, devido a uma cultura patrimonialista arraigada, são vistos como entraves para o avanço dos indicadores. A nível local, a corrupção e cooptação dos agentes públicos pelos privados ainda é de ocorrência comum, o que acaba refletindo no percentual de implementação de instrumentos de gestão ambiental pública municipal eficientes. (Leme, 2016).

Tabela 2 - Proporção da implementação dos instrumentos de gestão ambiental nos municípios do Nordeste - Ano 2017.

\begin{tabular}{c|c|c|c|c}
\hline $\begin{array}{c}\text { Unidade } \\
\begin{array}{c}\text { Federativa/Re } \\
\text { gião }\end{array}\end{array}$ & $\begin{array}{c}1 \text { - Existência - } \\
\text { Secretaria } \\
\text { municipal } \\
\text { exclusiva do meio } \\
\text { ambiente }\end{array}$ & $\begin{array}{c}\text { 2 - Existência - } \\
\text { Conselho Municipal } \\
\text { de Meio Ambiente }\end{array}$ & $\begin{array}{c}3 \text { - Existência de } \\
\text { Fundo Municipal } \\
\text { de Meio } \\
\text { Ambiente }\end{array}$ & $\begin{array}{c}4 \text { - O município possui Plano de } \\
\text { Gestão Integrada de Resíduos Sólidos } \\
\text { nos termos estabelecidos na Política } \\
\text { Nacional de Resíduos Sólidos. }\end{array}$ \\
\hline Maranhão & 52,07 & 39,17 & 30,88 & 29,03 \\
\hline Piauí & 23,21 & 25,45 & 15,63 & 17,41 \\
\hline Ceará & 25,00 & 85,33 & 36,41 & 54,89 \\
\hline $\begin{array}{c}\text { Rio Grande do } \\
\text { Norte }\end{array}$ & 14,37 & 50,90 & 18,56 & 27,54 \\
\hline Paraíba & 10,76 & 26,91 & 6,73 & 52,02 \\
\hline Pernambuco & 10,27 & 40,00 & 21,08 & 42,70 \\
\hline Alagoas & 24,51 & 29,41 & 15,69 & 59,80 \\
\hline Sergipe & 21,33 & 66,67 & 48,00 & 73,33 \\
\hline Bahia & 13,91 & 84,41 & 68,82 & 22,06 \\
\hline Nordeste & $\mathbf{2 1 , 0 1}$ & $\mathbf{5 2 , 9 5}$ & $\mathbf{3 3 , 0 5}$ & $\mathbf{3 6 , 3 4}$ \\
\hline
\end{tabular}

Fonte: Elaboração dos autores com base nos dados do IBGE (2017).

O Fundo Municipal de Meio Ambiente é um instrumento institucional utilizado para a obtenção de recursos, os quais serão utilizados para a execução de ações que visam a preservação e conservação ambiental. (RODRIGUES, et. al., 2016). Quanto a esse instrumento de gestão, observa-se que os municípios concentrados nos nove estados nordestinos apresentam em média, percentual de apenas $33,05 \%$.

Uma justificativa que pode ser considerada para esse baixo nível de implementação de um Fundo Municipal de Meio Ambiente é a dificuldade enfrentada no processo. A criação de fundos deve ser autorizada por lei e as normas para tal constam na Lei $\mathrm{n}^{\circ}$ 4.320/1964, art. 71 a 74. Ademais, a não existência de fundos municipais de meio ambiente privam a arrecadação do pagamento de multas pelo município por crimes ambientais, sendo o valor destinado ao estado ou à união. (Carvalho, et. al., 2005).

A Política Nacional de Resíduos Sólidos apresenta relevância considerável no tocante à questão sustentável pelo fato de definir planos, programas, objetivos e prazos que acabam por obrigar os principais agentes do mercado a prover a destinação 
adequada dos resíduos. (Demajorovic; Migliano, 2013). A partir da observação dos dados referentes ao ano de 2017, verifica-se que dentre os municípios do Nordeste, apenas um percentual de 36,34\% possui um Plano de Gestão Integrada nos termos estabelecidos na PNRS, o que sinaliza a necessidade de haver maior disseminação da importância de tal política para as condições ambientais existentes no território analisado.

As discussões acerca do gerenciamento correto dos resíduos sólidos são crescentes, uma vez que a alta quantidade disposta na natureza, em lixões a céu aberto, compromete diretamente os ideais de sustentabilidade. O tratamento dos resíduos é considerado custoso e, portanto, necessita de um planejamento específico.

No referente à existência de secretaria específica, Leme (2016) afirma ter esse instrumento, fundamental importância. No entanto, de acordo com os dados colhidos, o percentual dos municípios do Nordeste que possuem Secretaria Municipal exclusiva do Meio Ambiente é somente 21,01\%. A autora salienta que uma das questões que pode influenciar negativamente o processo é o fato de que em vários municípios, a promoção da gestão ambiental ocorre em secretaria conjunta com outras políticas públicas. Evidencia ainda que a existência de um órgão gestor exclusivo não garante a autonomia para as políticas públicas ambientais, uma vez que, a prefeitura pode ter secretaria exclusiva do meio ambiente e ainda assim, a agenda ambiental ser secundária.

O estudo mostrou que os modelos de gestão do meio ambiente nos municípios da Região Nordeste apresentam fragilidades quanto ao nível de implementação dos instrumentos de gestão. Conforme salienta Leme (2016), a falta de uma base social que legitime a representação e o favorecimento de interesses particulares, facilitam a omissão de vícios antigos ainda existentes na administração pública, a exemplo do patrimonialismo, clientelismo, coronelismo e mandonismo. O âmbito local pode favorecer as oportunidades de participação política e de relegitimação do Estado, mediante a proximidade entre o ente federado e os cidadãos.

\section{Considerações Finais}

O presente artigo teve por objetivo analisar o nível de implementação dos instrumentos de gestão ambiental nos municípios nordestinos, bem como identificar os estados com maiores e menores níveis de gestão. A conclusão mais direta do estudo é que há ainda uma omissão expressiva dos municípios nordestinos no tocante a gestão ambiental.

Mesmo após 29 anos da promulgação da CF/88 e mais especificamente 36 anos da implementação da PNMA, é possível verificar que os municípios nordestinos não trouxeram para si as responsabilidades que lhes foram atribuídas. Essa condição é perceptível a partir do baixo IGA nos municípios em análise. Essas fragilidades intrínsecas ao baixo nível de implementação de gestão ambiental contribuem para a redução da capacidade do município interferir positivamente no arrefecimento da degradação dos recursos ambientais, além de comprometer substancialmente a qualidade de vida da população. Por fim, compromete a atuação do município como agente catalizador das políticas públicas em âmbito local, visto que a sua capacidade instalada se encontra limitada e, em alguns casos, há ausência de alguns mecanismos.

Alguns fatores podem ser considerados responsáveis por tal problemática, no entanto, dois merecem destaque: (i) há pouco interesse dos gestores municipais em implementar os mecanismos básicos de gestão ambiental, tendo em vista que não há obrigatoriedade da efetivação dos respectivos instrumentos para a realização do planejamento, execução e monitoramento das políticas ambientais em escala local. Apesar disso, na ausência dos instrumentos o Município não tem como interferir positivamente na gestão ambiental local; (ii) a gestão ambiental não é vista como prioridade nos municípios analisados. O diálogo inter federativo pode favorecer a troca de experiências e o fomento à discussão em Conselhos ou fóruns com o envolvimento da população, que por encontrar-se mais próxima dos gestores, no caso dos municípios, pode exercer melhor o papel de influenciadora para a implementação de políticas. 
A partir da presente análise, foi possível observar que os casos mais críticos se encontram nos estados do Piauí, Paraíba e Pernambuco, os quais apresentaram maior quantidade de municípios que não implementaram nenhum dos instrumentos de gestão considerados, 115, 76 e 68, respectivamente. Outro fator analisado que demonstra o baixo índice de implementação nos mesmos é a quantidade de municípios que implementaram todos os instrumentos considerados: Piauí (3), Paraíba (3) e Pernambuco (5).

Acredita-se que uma possível fragilidade do presente estudo se encontra principalmente na questão temporal, uma vez que a análise se deu apenas em um ano específico (2017). No entanto, tal limitação pode ser justificada pelo fato que não há dados referentes aos quatro instrumentos considerados em anos anteriores nem posteriores, situação essa que possibilitaria uma análise comparativa.

As principais contribuições da pesquisa foram a abordagem feita acerca do processo histórico que envolve as discussões ambientais e do papel da gestão ambiental municipal na execução de políticas públicas relacionadas ao meio ambiente; e a criação do Índice de Gestão Ambiental (IGA-NE). Como sugestão para trabalhos futuros, propõe-se um estudo acerca da implementação dos quatro instrumentos de gestão analisados na presente pesquisa a nível nacional, para verificar se nos 5.568 municípios brasileiros o IGA apresenta o mesmo comportamento (baixo).

\section{Referências}

Araújo, S. M. V. G. (2015). Meio Ambiente e Constituição Federal. In: Roseli Sena Ganem (Org.) Legislação Brasileira sobre Meio Ambiente: Fundamentos Constitucionais e Legais. Câmara dos Deputados.

Ávila, R. D. \& Malheiros, T. F. (2012). O Sistema Municipal de Meio Ambiente no Brasil: Avanços e Desafios. Saúde Soc., $21,33-47$.

Barbieri, J. C. (2011). Gestão Ambiental Empresarial. Saraiva, e3.

Barbieri, J. C. (2016). Gestão Ambiental Empresarial. Saraiva, e4.

Benjamin, A. H. V. et al. (1999). Introdução ao direito ambiental brasileiro. Revista de direito ambiental, $14,48$.

Bittar, C. S. (2016). Análise da gestão ambiental municipal por meio da utilização da metodologia peir: um estudo de caso na Lagoa Feia em Formosa-GO. Brasília: Companhia de Planejamento do Distrito Federal, 20.

Booysen, F. (2002). An overview and evaluation of composite indices of development. Social Indicators Research, 59 (2), $115-151$.

Borges, L. A. C., Rezende, J. L. P. \& Pereira, J. A. A. (2009). Evolução da Legislação Ambiental no Brasil. Revista em Agronegócios e Meio Ambiente, 2 (3), 447-466.

Boschetti, F. A. \& Bacarji, A. G. (2009). Instrumentos de Gestão Ambiental: Uma ferramenta para a Competitividade. Resende. AEDB.

Braga, P. B. (2012). Análise do Programa Selo Município Verde como uma ferramenta operacional na gestão ambiental no Estado do Ceará. (Mestrado em Economia Rural) - Universidade Federal do Ceará, Fortaleza, BR.

Brasil. (2021) Constituição da República Federativa do Brasil - 1988. https://www2.senado.leg.br/bdsf/bitstream/handle/id/518231/CF88_Livro_EC9 1_2016.pdf.

Brasil. (2021). Lei $n^{\circ}$ 6.938, de 31 de agosto de 1981. https://www2.camara.leg.br/legin/fed/lei/1980-1987/lei-6938-31-agosto-1981-366135-publicacaooriginal1-pl.html.

Brasil. (2021). Política Nacional de Resíduos Sólidos - 2010. http://www.planalto.gov.br/ccivil_03/_ato2007-2010/2010/lei/112305.htm.

Booysen, F. (2002). An overview and evaluation of composite indices of development. Social Indicators Research, 59 (2), $115-151$.

Bonzi, R. S. (2013). Meio século de Primavera Silenciosa: um livro que mudou o mundo. Revista Desenvolvimento e Meio Ambiente, Curitiba, 28 , p. $207-215$.

Bruschi, D. M., Ribeiro, M. A., Peixoto, M. C. D., Santos, R. C. S. \& Franco, R. M. (2002). Manual de saneamento e proteção ambiental para os municípios. Belo Horizonte: Fundação Estadual do Meio Ambiente, e3.

Câmara, J. B. D. (2013). Governança Ambiental no Brasil: Ecos do Passado. Revista de Sociologia e Política, 21 (46), $125-146$.

Carvalho, P. G. M., Oliveira, S. M. C., Barcellos, F. C. \& Assis, J. M. (2005). Gestão local e meio ambiente. Revista Ambiente e Sociedade, São Paulo, 8 (1), 119.

Cezaré, J. P. (2009). Conselhos Municipais e Governança: Uma Análise do Conselho de Representantes de Paranapiacaba e Parque Andreense do Município de Santo André - SP. (Mestrado em Saúde Pública) - Universidade de São Paulo, São Paulo, BR. 
Chiesa, M. A. S. (2009). Gestão Ambiental: Entraves e Perspectivas para a municipalização no Estado do Espírito Santo.

Demajorovic, J. \& Migliano, J. E. B. (2013). Política Nacional de Resíduos Sólidos e suas implicações na cadeia da Logística Reversa de Microcomputadores no Brasil. Gestão \& Regionalidade, 29 (87), 64-80.

Felizola, M. P. M. \& Costa, F. B. (2012). O Ambientalismo em Sergipe - Um percurso histórico dos movimentos ambientais entre 1983-2011. Revista Brasileira de História \& Ciências Sociais, 4 (8), 317-337.

Ferreira, A. \& Ravena, N. (2017). A Importância da Política Nacional do Meio Ambiente para Legislação Ambiental Brasileira. Anais do II Congresso Amazônico de Meio Ambiente e Energias Renováveis, Belém-PA.

Gomes, A. (2008). Legislação Ambiental e Direito: Um Olhar sobre o Artigo 225 da Constituição da República Federativa do Brasil. Revista Científica Eletrônica de Administração, 8 (14), 1-8.

Instituto Brasileiro de Geografia e Estatística (IBGE). (2017). Perfil dos municípios brasileiros — 2017. Pesquisa de informações básicas municipais. Coordenação de população e indicadores sociais. IBGE. <http://www.ibge.gov.br/home/estatistica/economia/perfilmunic/2017/>.

Jacobs, R. \& Goddard, M. (2007). How do performance indicators add up? an examination of composite indicators in public services. Public Money \& Management's, 27 (2), 103-110.

Leme, T. N. (2016). Governança Ambiental no Nível Municipal. In: Adriana M. M. Moura (Org.) Governança Ambiental no Brasil: Instituições, atores e Políticas Públicas. Brasília: Ipea.

Leme, T. N. (2010). Os Municípios e a Política Nacional do Meio Ambiente. Planejamento e Políticas Públicas. 35.

Lima, P. V. P. S., Sousa, J. S. S., Araújo Sobrinho, A. M., Faustino, J. C. S. \& Casimiro Filho, F. (2014). Gestão municipal da segurança pública: responsabilidade dos municípios brasileiros no combate à violência. Revista Políticas Públicas, 18 (2), 399-414.

Louro, C. A. L. \& Menezes, J. (2012). O Planejamento na Gestão Ambiental Urbana dos Municípios Brasileiros. Caderno de Estudos Geoambientais, 3 (1), 6275 .

Miranda, G. M. (2012). Indicadores do potencial de gestão municipal de gestão municipal de recurso hídrico. (Dissertação de mestrado) - Universidade Estadual Paulista, BR.

Moraes, A. C. R. (2003). Ordenamento territorial: uma conceituação para o planejamento estratégico. In: Ministério da Integração Nacional. Para pensar uma política nacional de ordenamento territorial: anais da oficina de sobre a Política Nacional de Ordenamento Territorial. Ministério da Integração Nacional.

Moura, A. M. M. (2016). Trajetória da Política Ambiental Federal no Brasil. In: Adriana M. M. Moura (Org.) Governança Ambiental no Brasil: Instituições, atores e Políticas Públicas. Ipea.

Nascimento, D. T. (2008). Fatores determinantes da gestão ambiental municipal: um estudo inicial. In: IV Encontro Nacional da Anppas, 2008.

Nunes, M. R., Philippi Junior, A. \& Fernandes, V. (2012). Gestão Ambiental Municipal: objetivos, instrumentos e agentes. Revista Brasileira de Ciências Ambientais, 23.

Pereira, C. H. R. S. (2014). A Questão dos Municípios como Entidades Federativas na Constituição Federal de 1988: Uma Análise Histórica e Comparada. (Graduação em Direito) - Universidade Federal do Paraná.

Pott, C. M. \& Estrela, C. C. (2017). Histórico Ambiental: Desastres Ambientais e o Despertar de um Novo Pensamento. Estudos Avançados, $271-283$.

Prodanov, C. C. \& Freitas, E. C. (2013). Metodologia do trabalho científico: métodos e técnicas da pesquisa e do trabalho acadêmico. Novo Hamburgo: Feevale. e2.

Quintas, J. S. (2005). Introdução à gestão ambiental pública. IBAMA. e2.

Redin, E. \& Silveira, P. R. C. (2012). Política Ambiental Brasileira: limitações e desafios. Caderno de Pesquisa Interdisciplinar em Ciências Humanas, Florianópolis, 13 (103), 163-168.

Rocha, J. M. (2003). Política Internacional para o Meio Ambiente: Avanços e Entraves pós Conferência de Estocolmo. Revista Ciências Administrativas, Fortaleza, 9 (2), 229-240.

Rodrigues, C. B., Oliveira, M. R. R., Lima, P. V. P. S. \& Casimiro Filho, F. (2016). Instrumentos de gestão ambiental em municípios do semiárido brasileiro. Revista Brasileira de Gestão Ambiental e Sustentabilidade, 3 (5), 101-112.

Rodrigues, G. S. S. C. \& Colesanti, M. T. M. (2008). Educação Ambiental e as Novas Tecnologias de Informação e Comunicação. Sociedade e Natureza, 5156.

Seiffert, M. E. B. (2009). ISO 14001 Sistemas de Gestão ambiental: implantação objetiva e econômica. (3a ed.), Atlas.

Sousa, J. S., Minervino, D. L., Lima, P. V. P. S., Rocha, L. A. \& Oliveira, M. R. R. (2017). Instrumentos de gestão da assistência social: uma análise da realidade dos municípios brasileiros. Revista de Políticas Públicas, 21 (1), 283-302.

Sousa, M. C., Lima, P. V. P. S. \& Khan, A. S. (2015). Mecanismos de gestão municipal e a promoção dos direitos humanos. Revista de Administração Pública, 49 (4), 985-1009. 
Research, Society and Development, v. 10, n. 12, e40101220072, 2021

(CC BY 4.0) | ISSN 2525-3409 | DOI: http://dx.doi.org/10.33448/rsd-v10i12.20072

Tannous, S. \& Garcia, A. (2008). Histórico e Evolução da Educação Ambiental, através dos Tratados Internacionais sobre o Meio Ambiente. Nucleus, Ituverava, $5(8)$.

Toledo, S. R. B. (2005). Indicadores da capacidade de gestão ambiental urbana dos governos locais nas cidades médias do estado de São Paulo. (Mestrado em geografia) - Universidade Estadual de Paulista.

Vieira, E. B., Rocha, M. C., Silva, M. C. \& Pereira Júnior, J. P. (2020). Legislação Ambiental no Contexto Evolutivo Internacional e Nacional. Revista Jurídica, $20(1), 58-80$. 